\title{
A Prospective Study of Sarmiento's Functional Cast Bracing Technique In Management Of Closed Tibial Shaft Fractures
}

\author{
Dr. Rohan Maske ${ }^{1}$, Prof. S. Nongthon Singh $^{2}$, Prof. A.Mahendra Singh ${ }^{3}$, \\ Prof. S. N. Chishti ${ }^{4}$, Assistant Prof. Roel Langshong ${ }^{5}$, Dr. Pranav Masatwar ${ }^{6}$, \\ Dr.Sagnik Mukherjee ${ }^{7}$, Dr. Wobemo Lotha ${ }^{8}$ \\ 1,2,3,4,5,6,7,8 (Department Of Orthopaedics, Regional Institute Of Medical Sciences,Manipur University,Imphal \\ Manipur, India
}

\begin{abstract}
Thirty five patients with diaphyseal fractures of the tibia were treated with use of functional cast bracing technique, between September 2014 and august 2016 at RIMS Hospital, Imphal. Patients aged between 17 to 75 years were included in the study. After the initial treatment in casuality, a long leg cast was applied to the affected leg and closed reduction was attempted. On satisfactory reduction, the patients were admitted and allowed partial weight bearing as comfortable and tolerable by the patients. After confirming the clinical and radiological signs of callus formation, the long leg cast was replaced with a functional cast brace, which facilitated the movements at the knee and ankle joints. Active range of motion exercises with partial weight bearing was encouraged. The patients were followed up regularly on opd basis, and assesed for union clinically and radiologically.

In the present study, the mean age of the patients was 48 years, with even distribution of males and females. RTA was the most common mode of injury accounting for 29(82.65\%) cases. Spiral fractures - accounted for $14(40 \%)$ fractures.

The average time of application of the functional cast brace was 4.07 weeks after the injury. the Mean healing time for complete union of fracture was 18.42 weeks.The mean shortening at union was $6.73 \mathrm{~mm}$. $89 \%$ fractures healed with a shortening of $10 \mathrm{~mm}$ or less.

Of the 35 fractures showing complete union, 14(40\%) fractures united with varus angulation, with a mean varus angulation of 5.5 degree and $8(22.8 \%)$ fractures united with valgus angulation, with a mean valgus angulation of 5.18 dgree. 13 fractures united with no angulation in the coronal plane, $7(20 \%)$ fractures united with anterior angulation, with a mean anterior angulation 4.64 degree and $12(34.28 \%)$ fractures united with posterior angulation with a mean posterior angulation of 5.91 degree. 16 fractures united with no angulation in sagittal plane.

The magnitude of angular deformity and shortening in fractures treated with functional cast bracing technique were within acceptable limits, as evident by the assessment of mean shortening and mean angular deformity and its comparison with the results of other similar studies.

These findings appear to support our concept that function of the extremity is beneficial to osteogenesis and that closed, minimally displaced diaphyseal tibial fractures can be satisfactorily stabilized and managed using the functional cast bracing method.

Keywords: functional, cast brace, tibia, diaphyseal
\end{abstract}

\section{Introduction}

Tibial fractures occur in both high energy trauma, such as motor vehicle, winter sports (eg. skiing), and cycling accidents, and low energy trauma, such as falls, contact sports, distance running, and other endurance or repetitive impact activities. Injuries caused by high energy trauma are more likely to involve complex and open tibia fractures and fractures in certain locations, such as the tibial plateau ${ }^{1}$

By the reason of its superficial location, tibial shaft fractures represent the most common site of long bone fractures. Tibia is the most commonly fractured long bone in the body Nicoll has stated , "Fractures of Tibia are important for two reasons. The first is that they are common; the second that they are controversial and anything that is both common and controversial must be important" ${ }^{\text {" }}$. We have still along way to go before the best method of treating a fracture of the shaft of the tibia can be stated with finality ${ }^{4}$-Sir John Charnly. In adults and children, closed tibial shaft fractures are the most common long-bone fractures. The elderly suffer many of these fractures from simple falls, and those with significant osteoporosis incur open or more complex fractures, often with high morbidity ${ }^{5}$.Both conservative and surgical techniques have been introduced in an effort to speed time to union while minimizing the occurrence of complications such as residual deformity, consolidation problems, refracture, infection, compartment syndrome, peripheral nerve injuries, anterior knee pain, joint stiffness and vascular complications. ${ }^{6,7}$ 
Numerous treatment methods exist, and excellent results have been reported for both conservative and surgical treatment. Methods include closed reduction and immobilization,closed reduction early weight bearing and function, locked intramedullary nailing, flexible intramedullary nailing,open reduction and plating, and external fixation. Treatment of closed tibial shaft fractures remains controversial, although there is a general agreement that low energy, stable fractures are best treated conservatively. Although anatomic alignment may be achieved more readily with surgical treatment, the penalty of increased surgical risks and costs to patient and financial cost to society should be considered before conservative treatment is abandoned for a particular fracture.Cast bracing (CB) of diaphyseal tibial fracture has shown success since its use from 1960's 9,10. It harvests the potential of the soft tissue for fracture stabilization by constraining them within a shell of brace, thus creating a hydraulic pressure-like effect that stabilizes the fracture The controlled motion allowed by the brace at the fracture site is conducive to steogenesis A long period of convalence is inherent even to an uncomplicated healing course of this notorious fracture. ${ }^{13}$

A major principle of functional fracture bracing is that early restoration of function and graduated weight bearing (in keeping with tolerance and the minute motion that results) is beneficial to fracture healing ${ }^{14}$

Functional fracture bracing was inspired by the patellar tendon bearing prosthesis which had recently been developed for below-knee amputees. This prosthesis had eliminated the traditional thigh corset and allowed the transfer of weight-bearing stresses from the soft tissues of the thigh to the patellar tendon and condyles of the proximal tibia. Anticipating that by a similar mechanism, a below-knee weight-bearing cast, moulded like a patellar-tendon-bearing prosthesis, would prevent shortening in axially unstable tibial fractures, the first below-knee functional cast was constructed Contrary to traditional practice, this new cast allowed full movement of the knee but immobilized the ankle. However, shortly afterwards it was realized that inclusion of the ankle and foot was unnecessary. The ankle was therefore freed and within a short time pre-fabricated plastic braces became an accepted form of treatment. ${ }^{16}$ Initial reports indicated a low rate of nonunion, no increase in shortening of the limb and angular deformities which were within acceptable levels. ${ }^{15,16}$

\section{Materials And Methods}

2.1 Study design: This was a prospective interventional study in which patients with diaphyseal fractures of tibia admitted in department of orthopaedics, RIMS hospital, Imphal- meeting the inclusion and the exclusion criteria (as given below) were included in the study.

\subsection{Set up}

The study was conducted in the Department of Orthopaedic Surgery, Regional Institute of Medical Sciences (RIMS), Imphal, Manipur

2.3 Duration of study

The study was conducted from September 2014 to August 2016.

\subsection{Study population}

All patients with diaphyseal fractures of tibia meeting the inclusion criteria irrespective of sex, admitted at RIMS hospital, IMPHAL

\subsection{Inclusion criteria}

1) Those who gave consent for the operation and study

2) Age:> 18 yrs

3) Type : closed fractures, type 1 open fractures with minimal soft tissue injury

4) Site: diaphyseal (from $5 \mathrm{~cm}$ distal to tibial tuberosity to seven centimeters proximal to ankle)

5) Energy: low energy, medium energy, undisplaced/minimally displaced high energy fractures.

6) Shortening: initial acceptable shortening not more than $15 \mathrm{~mm}$

\subsection{Exclusion criteria}

1. Fractures with neurovascular injury.

2. Fractures with compartment syndrome.

3. Open fracture with sever soft tissue loss.

4. Diabetic patients with neuropathy.

5. pathological fractures

6. Patients with rheumatoid arthritis

7. Ipsilateral femoral fracture.

8. Patients with Multiple injuries

9. Fracture with incomplete follow up.

\subsection{Sample size}

Thirty five patients of fracture shaft of tibia meeting inclusion and exclusion criteria 


\subsection{Study variables}

Age and sex of the patient, mode of injury, level of fracture, fracture patterns, duration for fracture healing were the study variables studies.

\subsection{Methods}

After the first aid and stabilization of patient in emergency room, Fractured limb was immobilized with below knee slab and plain radiographs of AP and lateral views of thigh including thigh, hip and knee, ankle joints were taken to assess the extent of fracture comminution, geometry and the dimensions of the fracture.

On admission to the ward, fractures requiring manipulation were reduced under regional anaesthesia / sedation and then placed in an above knee cast. Those not requiring manipulation were placed in an above knee cast under sedation. Patients were selected for treatment with functional bracing based on initial shortening and fracture pattern.

The patient was discharged, Once adequate alignment and or reduction was obtained and skin condition permitted, Partial weight bearing guided by pain tolerance was permitted in the long leg cast.

Reduction was considered acceptable if there was at least 50 percent cortical apposition as seen on anterio posterior and lateral radiographs, no more than 10 degrees of angulation in any direction, and no more than $1.5 \mathrm{~cm}$ of shortening

\section{Bracing technique}

Providing that the criteria discussed above are met, an above-the-knee cast was applied first, avoiding angular deformities and equinus position of the ankle. To aid in maximizing the desired corrections, the patient sits on a high table with the hip, knee, and ankle flexed to $90^{\circ}$. The cast held the knee in no more than $10^{\circ}$ of flexion. Walking was encouraged, with the degree of weight-bearing determined in accordance with the comfort and pain tolerance of the patients.

When the acute swelling has subsided, which is usually within ten days to four weeks after the fracture, the limb is placed in a custom-made cast brace with a hinged foot brace that allows movement at the ankle.

The leg was cleaned and cotton padding was applied. A plaster of paris cast was applied over the leg including the patella and malleoli. The foot brace was then positioned and the estimate of the level of malleoli and the hinge was taken to facilitate movement at the ankle joint. The brace was then fixed to the cast by applying plaster of paris over the brace arms. The cast is allowed to set for 10-15 mins. Movements at the ankle are checked for any obstruction or disturbance.

Partial weightbearing, ankle dorsiflexion and plantar flexion are encouraged after the cast brace application.

In the long leg cast, Initial weightbearing was accomplished with the aid of two axillary crutches, then gradually, as symptoms subsided and stability increased, to one crutch and so on. The patients were instructed to take short frequent walks, then sit with the extremity elevated. It is not advisable for patients to stand with non weight bearing on the hanging fractured extremity for long periods of time.

Time for weight bearing was determined on the basis of stability of fracture, the degree of cortical continuity , radiological evidence of fracture healing and comfort of the patient.

Serial Radiographs were used to determine the location, amounts of comminution and displacement and time of healing of fractures.

patients managed were followed up every 2 weeks in ortho opd rims imphal, For maximum of 6 to 8 wks after the injury and at monthly intervals thereafter up till the completion of treatment.

\subsection{Follow-up care:}

7-10 Days: Review xrays to ensure alignment is maintained.

4 Weeks : Review xrays to ensure alignment is maintained

6 Weeks: Review xrays to ensure alignment is maintained, Place in funcitonal brace at 4-6weeks according to the type of fracture, stability of fracture, the degree of cortical continuity, radiological evidence of fracture healing and comfort of the patient.

3 Months: Review xrays for union. Continue function brace until union.

6 Months: Return to full activity

Presence of bridging callus as seen on both anterio-posterior and lateral radiographs was taken as the radiological sign of fracture healing and the mean time for radiographic union was determined.Fractures which showed clinical and radiological signs of healing but required more than 30 weeks for complete union were to be considered delayed union.Fracture not united at nine months was to be considered as non union 


\subsection{Datacompilation:}

Data was compiled including Name, Age ,Sex, Address, Side of injury, Tibial fracture type and location, Associated injuries, Mechanism of injury,Date of application of functional cast brace, date of partial weight bearing, time for fracture healing (clinically and radiologically), date of complete weght bearing, limb length shortening at the time of union, angular deformity at the time of union.

Clinically, the patients were examined for swelling, abrasions, range of movement at the knee and ankle joints at the time of every follow up.

\subsection{Radiological assesment}

$\mathrm{X}$-ray leg full length with knee joint and ankle - AP and Lateral views

1. Circumferential callus formation - good/adequate/ poor

2 Visibility of fracture line - seen clearly / masked / not seen

3. Final angulation.

\subsection{Ethics}

All the participants are informed about the nature of the project and those agreed to participate were asked to sign the informed consent form. Participants were assumed that they could withdraw from the project at any time. The approval of the RIMS Research Ethics Board was taken.

\subsection{Conflict of interest: None}

\section{Observation And Results}

Patients were prospectively recruited over a 24-month period. A total of 40 patients met the criteria for inclusion. Of these, 37 agreed to participate. A total of 35 patients were randomly selected by chit method assisted by computer. No patients were lost to follow-up. The following results and observation were made at the end of the study.

3.1 Age: In the present 2(5.7\%) patients were of age group 18-25, 9(25.6\%) patients were of age group 26-40, 13(37\%)patients were of age group 41-55,

$8(22.5 \%)$ patients were of age group 56-70, and 3(8.5\%) patients were of age group 71-85

3.2 Sex incidence:

There were $17(48 \%)$ females and $18(52 \%)$ males in the present study.

3.3 Mode of Injury:

In the present study RTA was the most common mode of injury accounting for $29(82.65 \%)$ cases, self fall accounted for $2(5.7 \%)$ cases and fall from height accounted for $4(11.4 \%)$ of the cases.

\subsection{Pattern of Facture:}

In our study, transverse fractures accounted for 7(20\%) cases, communited fractures- $2(5.7 \%)$, oblique fractures - 12(35\%), spiral fractures $-14(40 \%)$ and there were no segmental fractures

\subsection{Level of fracture}

Fractures involving the middle $1 / 3$ rd accounted for $21(60 \%)$ cases, proximal $1 / 3^{\text {rd }}-3(9 \%)$ and distal $1 / 3^{\text {rd }}$ 11 (31) of cases in our study.

\subsection{Average Time of application of cast and braces :}

After achieving initial stabilisation and acceptable reduction in a above knee cast, a functional cast brace was applied to the affected limb. Of the 35 patients 18 patients were applied the brace between 3 weeks to 4 weeks after injury, 14 patients were applied the brace between 4 weeks to 5 weeks after the injury, 3 patients were applied with the brace between 5 weeks to 6 weeks after injury.

\subsection{Mean healing time.}

On regular follow ups the fracture was assessed for the time of union on basis of the clinical findings and radiological confirmation. Of the 35 fractures,

$13(42 \%)$ fractures showed union by end of 18 weeks, $2(5.7 \%)$ fractures showed union by end of 15 weeks,

$5(14.25 \%)$ fractures showed union by the end of 16 weeks,

$6(17.1 \%)$ fractures showed union by the end of 17 weeks,

$5(14.25 \%)$ fracture showed union by end of 19 weeks,

$1(2.85 \%)$ fracture showed union by end of 20 weeks,

$1(2.85 \%)$ fracture showed union by end of 22 weeks,

$1(2.85 \%)$ fracture showed union by end of 30 weeks. 
$1(2.85 \%)$ fracture showed union by end of 32 weeks.

Of the 35 cases, 2 cases healed with delayed union, and no case was observed to have non union. Mean healing time was 18.42 weeks.

\subsection{Time of full weight bearing:}

Unsupported full weight bearing was started in $<16$ weeks in 5 patients, between 16 and 18 weeks in 16patients, between 18 weeks to 20 weeks in 12 patients and between 20 weeks and 22 weeks in 2 patient

\subsection{Complications:}

In the present study, of the total 35patients , 2 patients had delayed union, with healing time of 30 and 32 weeks. All fractures united by the 32 weeks and no fracture with non union was observed.4 patients had skin abrasions over the ankle region over the malleoli.Range of movement restriction at the knee joint and ankle joint was observed at follow ups. At the time of complete union, Of the 35 patients at the time of complete union, $31(88.57 \%)$ patients had full range of motion at knee and ankle joints. 3 patients had mild restriction of movements and 1 patient had moderate restriction of movements. No patient was observed to have severe range of movement restriction. In the present study, 26 cases were observed to have shortening. Of the 26 cases 10 cases had final shortening of $<5 \mathrm{~mm}, 12$ cases had final shortening of $5-10 \mathrm{~mm}, 2$ cases had shortening of $10-15$ $\mathrm{mm}$, and 2 cases had shortening of $15-20 \mathrm{~mm}$ at the time of union. 9 fractures healed without any shortening

Angulations in Coronal plane: In present study, of the 35 fractures showing complete union, 14 fractures united with varus angulation, 8 fractures united with valgus angulation and 13 fractures united with no angulation in the coronal plane.

Angulations in sagittal plane: in present study, of the 35 fractures showing complete union, 7 fractures united with anterior angulation, 12 fractures united with posterior angulation and 16 fractures united with no angulation in sagittal plane

In the present study,the most common angular deformity observed in the fractures at the time of complete union was varus angulation followed by posterior angulation, valgus angulation and anterior angulation respectively. i.e. varus(14)>posterior(12)>valgus(8)>anterior(7).

\section{Discussion}

In the present study RTA was the most common mode of injury accounting for $29(82.65 \%)$ cases, self fall accounted for $2(5.7 \%)$ cases and fall from height accounted for $4(11.4 \%)$ of the cases. Sarmiento et al ${ }^{18}$ in their study assessing 780 patients, $45 \%$ patients were following rta, 31\%patients had injury due to fall, and 8 $\%$ patients suffered injury due to direct blow. Batta $\mathrm{V}$ et al ${ }^{17}$ in their study assessing 68 cases, had 59 cases with injury due to RTA, and 6 cases with injury due to fall.

In our study, transverse fractures accounted for $7(20 \%)$ cases, communited fractures- $2(5.7 \%)$, oblique fractures - 12(35\%), spiral fractures - 14(40\%) and there were no segmental fractures.Sarmiento et $a^{18}$ in their study had 145(19\%) transverse fractures, 214(27\%) oblique fractures,158(20\%) spiral fractures,238(31\%) comminuted fractures Batta $\mathrm{V}$ et al ${ }^{17}$ reported $86 \%$ of the fractures in their study were oblique and spiral. Fractures involving the middle $1 / 3$ rd accounted for $21(60 \%)$ cases, proximal $1 / 3^{\text {rd }}-3(9 \%)$ and distal $1 / 3^{\text {rd }}$ $11(31 \%)$ of cases in our study. Sarmiento et $\mathrm{al}^{18}$ in their study had $86(11 \%)$ fractures involving the proximal third, 330(43\%) involving the middle third,339(44\%) involving the distal third of the tibia, and 25(3\%) fractures were segmental. Batta $\mathrm{V}$ et al ${ }^{17}$ in their study had $97 \%$ cases with fractures in mid and distal third of tibia.

Of the 35 patients 18 patients were applied the brace between 3 weeks to 4 weeks after injury, 14 patients were applied the brace between 4 weeks to 5 weeks after the injury, 3 patients were applied with the brace between 5 weeks to 6 weeks after injury. The average time of application of the functional cast brace was 4.07 weeks after the injury. Sarmiento et $\mathrm{al}^{18}$ in their study observed the mean time after injury for application of the functional cast brace as 3.8 weeks. Mahdi AA et $\mathrm{al}^{19}$ in their study observed the mean time of application of the functional brace after injury to be 4.8 weeks Mean healing time in the present study was 18.42 weeks. Sarmiento et $\mathrm{al}^{18}$ in their study observed that the mean time of healing for all fractures of tibia was 18.7 weeks.

Mahdi AA et $\mathrm{al}^{19}$ in their study observed the mean time for healing to be 17.2 weeks Hooper et $\mathrm{al}^{3}$ in their study observed the mean time for healing to be 18.3 weeks In the present study unsupported Full weight bearing was started in patients who were comfortable and can tolerate the pain, and showing signs of clinical and radiological union. Unsupported full weight bearing was started in $<16$ weeks in 5 patients, between 16 and 18 weeks in 16patients, between 18 weeks to 20 weeks in 12 patients and between 20 weeks and 22 weeks in 1 patient. The average time for starting unsupported weight bearing was 17.52 weeks. In the present study, 4 patients had skin abrasions over the ankle region over the malleoli. Brace adjustments and contouring were performed when necessary to ensure proper fitting of the brace. Sarmiento et al ${ }^{18}$ in their study observed that skin problems included 20 cases, with abrasions over malleoli. 2 patients had delayed union, with healing time of 30 and 32 weeks. Both fractures were comminuted, with one patient being elderly with tuberculosis on akt . 
Mahdi AA et al $^{19}$ in their study have observed 2 cases which had delayed union, which were attributed to the degree of soft tissue injury. In the present study, 26 cases were observed to have shortening. Of the 26 cases 10 cases had final shortening of $<5 \mathrm{~mm}, 12$ cases had final shortening of $5-10 \mathrm{~mm}, 2$ cases had shortening of $10-15 \mathrm{~mm}$, and 2 cases had shortening of $15-20 \mathrm{~mm}$ at the time of union. 9 fractures healed without any shortening The mean shortening at union was $6.73 \mathrm{~mm} .89 \%$ fractures healed with a shortening of $10 \mathrm{~mm}$ or less. Sarmeinto et al ${ }^{18}$ in their study observed that of the 780 fractures, $312(40 \%)$ fractures healed without shortening,468 (60\%) fractures healed with an average shortening of $7.1 \mathrm{~mm}(1-31 \mathrm{~mm}), 90 \%$ fractures healed with a shortening of $10 \mathrm{~mm}$ or less. Sarmiento et al ${ }^{21,22-24}$ has given different figures for shortening of tibia in his various studies ranging between $(0-25 \mathrm{~mm})$, but he stressed on the acceptable shortening to be not exceeding $12 \mathrm{~mm}$. Mahdi AA et $\mathrm{al}^{19}$ in their studies have estimated the range of shortening of tibia between (5.6-13.4mm.) with an average of ( $9.7 \mathrm{~mm}$.)

Batta V et al ${ }^{17}$ in their study observed the mean shortening to be $6.6 \mathrm{~mm}$ Sarmiento et $\mathrm{al}^{21}$ of the 391 patients, Three hundred and fifty-seven (91.2 per cent) of the patients had ten millimeters of final shortening or less, and 306 (78.3 percent) had a final angulation of 5 degrees or less. Digby JM et $\mathrm{al}^{20}$ observed radiologically the average shortening as $5 \mathrm{~mm}$ In present study, of the 35 fractures showing complete union, 14(40\%) fractures united with varus angulation, with a mean varus angulation of 5.5 degree.Of the 35 fractures $8(22.8 \%)$ fractures united with valgus angulation, with a mean valgus angulation of 5.18 dgree .13 fractures united with no angulation in the coronal plane.

In present study, of the 35 fractures showing complete union, 7(20\%) fractures united with anterior angulation, with a mean anterior angulation 4.64 degree. Of the 35 fractures, $12(34.28 \%)$ fractures united with posterior angulation with a mean posterior angulation of 5.91 degree. 16 fractures united with no angulation in sagittal plane Sarmiento et $\mathrm{al}^{18}$ in their study observed that $385(49 \%)$ fractures healed with varus angulation (115 degree ) of which $289(75 \%)$ healed with 5 degree angulation or less. Th mean varus angulation was 4.8 degree. In their study, There were 125 fractures (16\%) that healed with valgus angulation(1-12 degree). Of these $110(88 \%)$ with 5 degree of valgus angulation or less. Mean valgus angulation was 4 degree, They found healing in anterior angulation in 154 fractures(20\%) with anterior angulation (1-15 degree), 120(78\%) with less than 6 degree of anterior angulation. The mean anterior angulation was 4.7. Posterior angulation of 1-18 degree was seen in 297 (38\%) fractures, 214(72\%) with angulation 5 degree or less. Mean posterior angulation of 4.9 degree Batta $\mathrm{V}$ et al ${ }^{17}$ in their study observed an average of 4.9 degree angulation in sagittal (antero-posterior ) plane, and average 5.1 degree angulation in coronal(varus-valgus) plane Mahdi $\mathrm{AA}$ et $\mathrm{al}^{19}$ in their study observed 7.5 degree mean angulation in 50\% patients,3-5 degree valgus angulation in 25\% patients, 5-7.5 degree angulation in $25 \%$ patients. Sarmiento ,Gersten and Sobol agreed that varus and posterior angulations were the most common deformities encountered at union In cadaveric studies examining the effect of varying tibial angular deformities on adjacent joints, articular contact pressures ily when angular changes exceeded 10 degree

Table. 1. Limb alignment standards deemed acceptable in the literature

\begin{tabular}{|c|c|c|c|}
\hline Study & Varus(degrees) & $\begin{array}{c}\text { Valgus(de } \\
\text { grees) }\end{array}$ & $\begin{array}{c}\text { Anterior/poste } \\
\text { rior (degrees) }\end{array}$ \\
\hline Nicoll & 10 & 10 & 10 \\
\hline $\begin{array}{c}\text { Statis and } \\
\text { rokkanen }\end{array}$ & 5 & 5 & 10 \\
\hline Jensen et al & 8 & 8 & 15 \\
\hline $\begin{array}{c}\text { Johner and } \\
\text { wruhs }\end{array}$ & 5 & 5 & 10 \\
\hline Haines et al & 4 & 4 & -- \\
\hline $\begin{array}{c}\text { Puno et al } \\
\text { Böstman }\end{array}$ & 10 & 10 & 20 \\
\hline Trafton & 5 & 5 & -- \\
\hline $\begin{array}{c}\text { Merchant \& } \\
\text { Dietz }\end{array}$ & 5 & 5 & 10 \\
\hline Collins et al. & 5 & 5 & $5-10$
\end{tabular}


Table 2. Limb shortening deemed acceptable in literature

\begin{tabular}{|l|l|}
\hline Study & Shortening \\
\hline Nico11 and & $10 \mathrm{~mm}$ \\
\hline $\begin{array}{l}\text { Statis } \\
\text { rokkanen }\end{array}$ & $20 \mathrm{~mm}$ \\
\hline Jensen et a1 & $13 \mathrm{~mm}$ \\
\hline Haines et a1 & $20 \mathrm{~mm}$ \\
\hline Puno et a1 & $10 \mathrm{~mm}$ \\
\hline Böstman & $15 \mathrm{~mm}$ \\
\hline Trafton & $10 \mathrm{~mm}$ \\
\hline Collins et al.
\end{tabular}

\section{Conclusion}

Considering the results of this prospective interventional study, with high rates of union, functional cast bracing for minimally displaced, closed fractures of tibia seems to be an acceptable modality of treatment The findings of this study appear to support our concept that functioning of the extremity is beneficial to osteogenesis and that closed minimally displaced, diaphyseal tibial fractures can be satisfactorily stabilized in functional cast braces. The assessment of magnitude of shortening and malalignment at the time of complete union in the fractures included in this study and its comparison with the data compiled from other similar studies reveals that the mean shortening and mean angular deformities observed with the use of cast bracing technique are within acceptable limits.

Although anatomic alignment may be achieved more readily with surgical treatment, the penalty of increased surgical risks and costs to patient and financial cost to society should be considered before conservative treatment is abandoned for a particular fracture. Functional cast bracing is a simpler, safer and acceptable alternative to surgical approach for minimally displaced, closed tibial diaphyseal fractures in patients unfit for surgery, and for treatment in far reached places with limited resources (eg. army).

\section{References}

[1]. Albuquerque RP, Hara R, Prado J. Epidemiological study on tibial plateau fractures at a level I trauma center. Acta Ortop Bras 2013;21(2):109-15.

[2]. Hooper GJ, Keddell RG, Penny ID. Conservative management or closed nailing for tibial shaft fractures: A randomised prospective trial. J Bone Joint Surg Br 1991;73(1):83-5.

[3]. Toivanen JAK.Treatment of low energy tibial shaft fractures.[dissertation].Tampere:Univ of Tampere;2001.

[4]. Jones RW. Fracture of shaft of long bones with displacement. In: Wilson JN, editor. Fractures and joint injuries. 10 ${ }^{\text {th }}$ ed. New York: Churchill Livingstone; 1998 p. 1078-84.

[5]. Schmidt AH, Finkemeier CG, Tornetta P. Treatment of closed tibial fractures. Instr Course Lect 2003;52(3):607-10.

[6]. Whittle PA, Wood WG. Fractures of lower extremity. In: Canale TS, Daugherty K, Jones L, editors. Campbell's Operative Orthopaedics. $11^{\text {th }}$ ed. Philadelphia: Mosby; 2003. p. 2754-88.

[7]. Toivanen JA, Honkonen SE, Koivisto AM, Jarvinen MJ. Treatment of low-energy tibial shaft fractures: plaster cast compared with intramedullary nailing. Int Orthop 2001;25(2):110-3.

[8]. Sarmiento A, Sharp FE, Ebramzadeh E, Normand P, Shankwiler J. Factors influencing the outcome of closed tibial fractures treated with functional bracing. Clin Orthop Relat Res 1995;315(2):8-24.

[9]. Kenwright J, Richardson JB, Cunningham JL. Axial movement and tibial fractures: a controlled randomised trial of treatment. J Bone Joint Surg Br 1991;73(4):654-9.

[10]. Petrisor BA, Bhandari M, Schemitsch E. Tibia and Fibula Fractures. In: Bucholz RW, Heckman DJ, Court-Brown CM, Tornetta P, editors. Rockwood and Greens fractures in adults. $6^{\text {th }}$ ed. Philadelphia: Lippincott Williams \& Wilkins;2006. p. $2080-143$.

[11]. Müller ME, Koch P, Schatzker J. Fractures of tibia. In: Nazarian S, editor. The Comprehensive Classification of Fractures of Long Bones. Berlin: Springer-Verlag;1990. p.148-91.

[12]. Haines JF, Williams EA, Hargadon EJ. Is conservative treatment of displaced tibial shaft fractures justified? J Bone Joint Surg Br 1984;66(1):84-8.

[13]. Bhandari M, Guyatt G, Tornetta P, Schemitsch EH, Swiontkowski M, Sanders D, et al. Randomized trial of reamed and unreamed intra medullary nailing of tibial fractures. J Bone Joint Surg Am 2008;90(12):2567-78.

[14]. Latt a L, Sarmiento A, Tarr R. The rationale of fun ctional bracing of fractures. Clin Orthop Relat Res 1980;146(4):28-36.

[15]. Sarmiento A. A functional below-knee cast for tibial fractures. J Bone Joint Surg Am 1967;49(1):855-75.

[16]. Sarmiento A. A functional below-knee brace for tibial fractures: a report on its use in one hundred thirty-five cases. J Bone Joint Surg Am 1970;52(1):295-311

[17]. Batta V, Dwyer AJ, Gulati A, PrakashJ, Mam MK, John B. No difference in the long term final functional outcome after nailing or cast bracing of high energy displaced tibial shaft fractures. J Trauma Manag Outcomes 2012;6(2):5-8.

[18]. Sarmiento A, Gersten LM, Sobol PA, Shankwiler JA, Vangsness CT. Tibial shaft fracture treated with functional braces: experience with 780 fractures. J Bone Joint Surg Br 1989;71(4):602-9.

[19]. Mahdi AA, Husain AH, Mustafa LM. Functional Bracing in the Management of Diaphyseal Fractures of Tibia. The Iraqi Postgraduate Medical Journal 2008;7(4):295-303.

[20]. Digby JM, Holloway GM, Webb JK. A study of function after tibial cast bracing. Injury 1983;14(5):432-9. 
[21]. Sobol PA, Sarmiento A, Sewhoy AL, Ross SD, Racette WL, Tar RR. Prefabricated functional braces for the treatment of fracture of the tibial diaphysis. J bone Joint Surg Am 1984;66(9):1328-39.

[22]. Martinez A, Sarmiento A, Latta LL. Closed fractures of the proximal tibia treated with a functional brace. Clin Orthop Relat Res 2003;417(5):293-302.

[23]. Sarmiento A. The behavior of closed tibial fractures: clinical/radiological correlations. J Orthop Trauma 2000;14(3):199-205.

[24]. Sarmiento A, Burkhalter WE, Latta LL. Functional bracing in the treatment of delayed union and non-union of tibia. Int Orthop 2003;27(1):26-9.

[25]. Mckellop HA, Sigholm G, Redfern FC. The effect of simulated fracture-angulations of tibia on cartilage pressures in knee joint. J Bone Joint Surg Am 1991;73(9):1382-91.

[26]. Tarr RR, Resnik CT, Wagener KS, Sarmiento A. Changes in tibiotalar joint contact areas following experimentally induced tibial angular deformities. Clin Orthop 1985;199(2):72-80.

[27]. Trafton PG. Closed unstable fractures of tibia. Clin Orthop 1988;230(4):58-67.

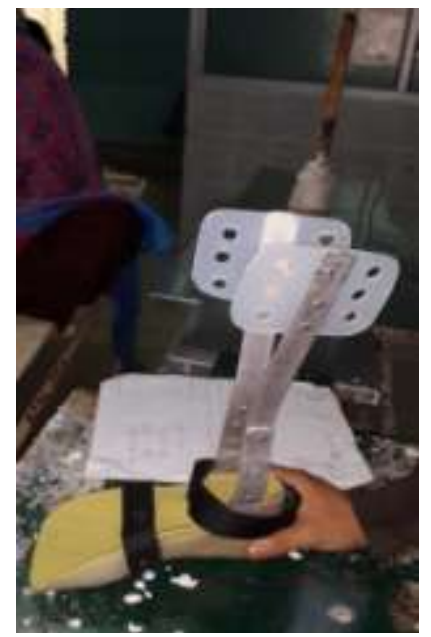

Fig. 1 Hinged foot splint used in the cast bracing

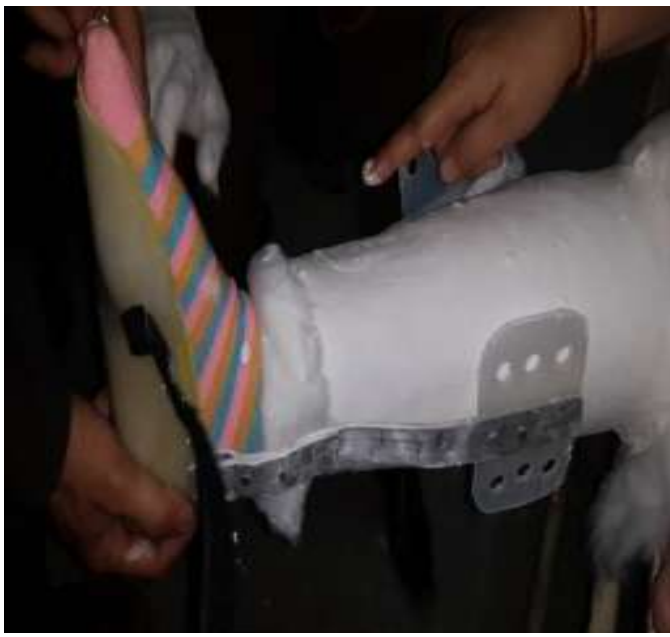

Fig.2.The foot is covered as per the comfort of the patientwith a socks or a chappal, and the hinged foot brace is applied. The level of the hinges and the ankle joint are adjusted to facilitate free ankle movement

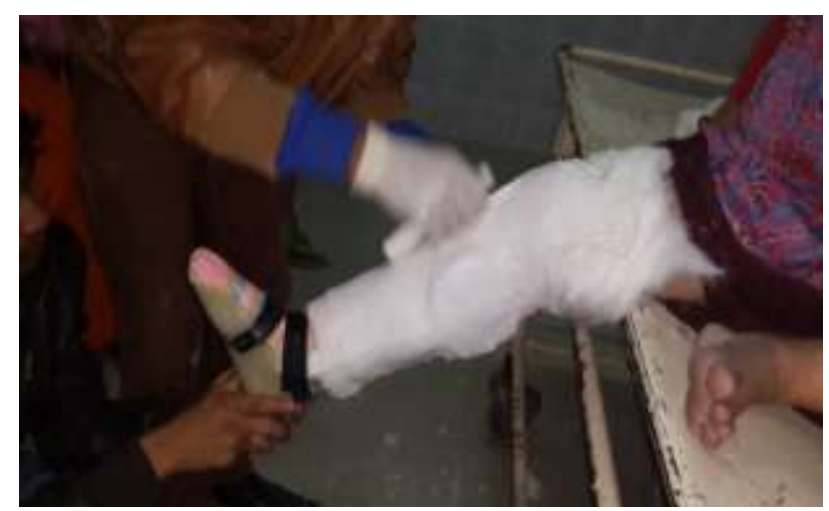

Fig. 3. The brace is fixed in position using the plaster of paris application 

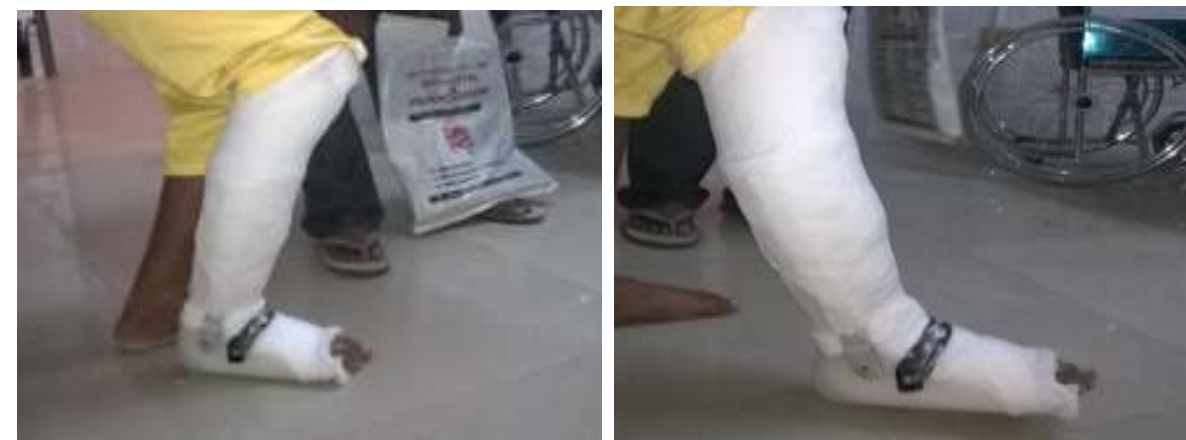

Fig.4. Partial weight bearing, dorsiflexion and plantar flexion encouraged soon after the application of the cast
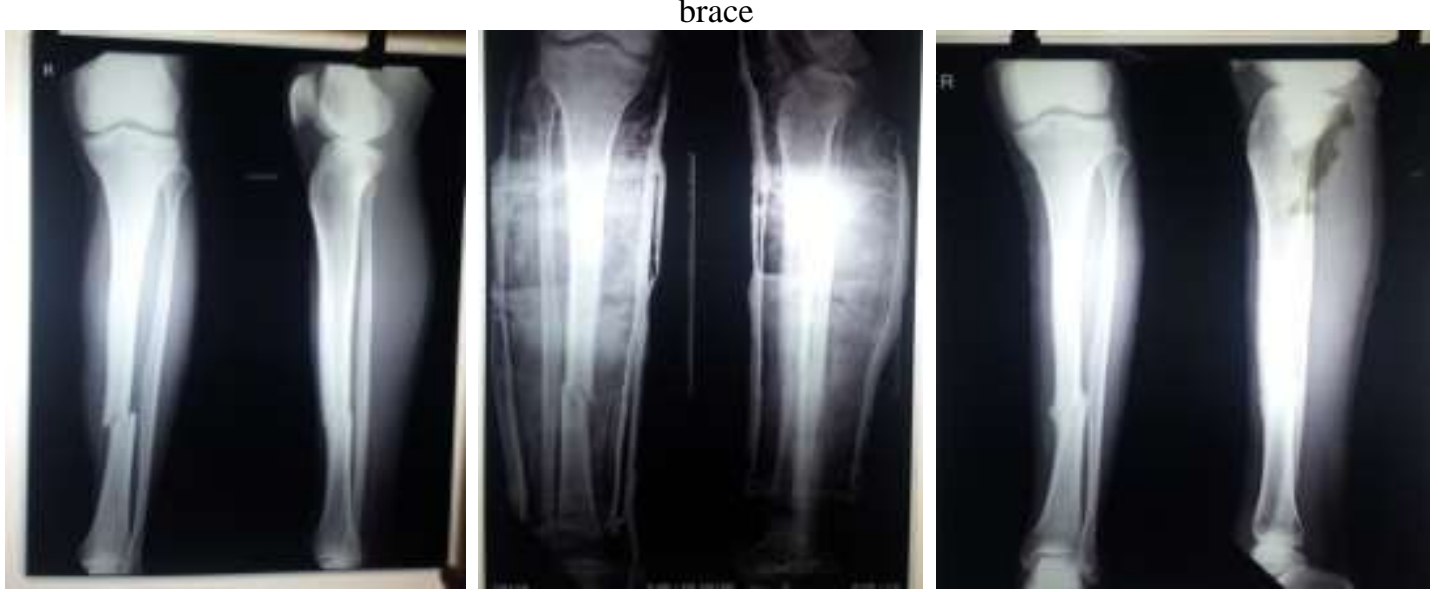

Fig.5. xrays at the time of injury and after cast brace application Fig.6. xray at the time of union and brace removal

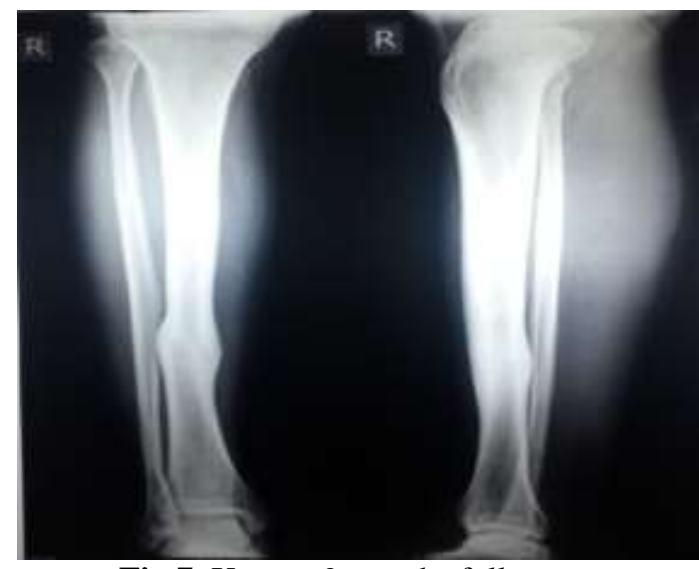

Fig.7. Xray at 9 months follow up

\section{Authors' profile:}

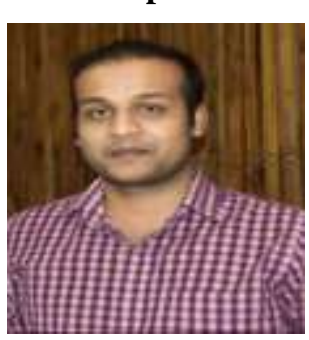

Dr. Rohan Maske is a Third year Post graduate trainee at Prestigious Regional Institute Of Medical Sciences, Imphal, Manipur. He has passed his M.B.B.S undergraduation from the renowned institute Seth.GS Medical College and KEM hospital, Mumbai.

Dr. S. Nongthon Singh is the Professor and Head of Department, Department Of Orthopaedics, Regional Institute of Medical Sciences, Imphal, Manipur, India.

Dr. A. Mahendra Singh, Professor, Department Of Orthopaedics, Regional Institute of Medical Sciences, Imphal, Manipur, India.

Dr. S.N. Chishti , Professor, Department Of Orthopaedics, Regional Institute of Medical Sciences, Imphal, Manipur, India.

Dr. Roel Langshong, Assistant Professor, Department of Orthopaedics, Regional Institute Of Medical Sciences, Imphal , Manipur, India.

Dr. Pranav Masatwar is a postgraduate trainee, Department of Orthopaedics, Regional Institute Of Medical Sciences, Imphal, Manipur, India.

Dr. Sagnik Mukherjee is a postgraduate trainee, Department of Orthopaedics, Regional Institute Of Medical Sciences, Imphal, Manipur, India.

Dr. Wobemo Lotha is a postgraduate trainee, Department of Orthopaedics, Regional Institute Of Medical Sciences, Imphal, Manipur, India. 